\title{
Transient Ischemic Stroke due to Hyperhomocysteinemia: A Rare Case Report
}

\author{
${ }^{1}$ Ashok Jagtap, ${ }^{2}$ Ankit Gupta, ${ }^{3}$ Prakhar Mohniya, ${ }^{4}$ Priyanka Karande
}

\begin{abstract}
Introduction: Cerebrovascular disease in childhood is relatively rare. Recently, there has been much interest in homocysteine, a sulfur-containing amino acid, as an important risk factor for vascular diseases including stroke. We report the case of a 13-year-old girl presented with ischemic stroke due to hyperhomocysteinemia.
\end{abstract}

Case report: This case report describes a 13-year-old girl with repeated episodes of hemiplegia due to hyperhomocysteinemia.

Conclusion: There are strong clues in favor of a causal relationship between hyperhomocysteinemia and athero-trombotic diseases. Homocysteine levels can be lowered effectively by a combination therapy of folic acid, vitamin B12, and vitamin B6.

Keywords: Hemiplegia, Hyperhomocysteinemia, Ischemic stroke.

How to cite this article: Jagtap A, Gupta A, MohniyaP, KarandeP. Transient Ischemic Stroke due to Hyperhomocysteinemia: A Rare Case Report. Int J Recent Surg Med Sci 2016;2(1):28-29.

\section{Source of support: Nil}

Conflict of interest: None

\section{INTRODUCTION}

Cerebrovascular disease in childhood is relatively rare. The incidence for ischemic and hemorrhagic strokes together is 2.7 cases per 100,000 population per year. ${ }^{1}$ Despite recent advances, only two-third of all strokes can be attributed to known causal risk factors. ${ }^{2}$ Recently, there has been much interest in homocysteine, a sulfurcontaining amino acid, as an important risk factor for vascular diseases including stroke, independent of the long-recognized factors, such as, hyperlipidemia, hypertension, diabetes mellitus, and smoking, although its association was described many decades ago. During the last decade, numerous studies observed a strong positive correlation between hyperhomocysteinemia and ischemic stroke, while others could not establish the same.

\footnotetext{
${ }^{1}$ Associate Professor, ${ }^{2-4}$ Resident

${ }^{1-4}$ Department of Paediatrics, Krishna Institute of Medical Sciences, Karad, Maharashtra, India
}

Corresponding Author: Ashok Jagtap, Associate Professor Department of Paediatrics, Krishna Institute of Medical Sciences, Karad, Maharashtra, India, Phone: +919130273627 e-mail: drashokjagtap@yahoo.com
This report describes a girl with repeated episodes of hemiplegia.

\section{CASE REPORT}

A 13-year-old girl was brought in the emergency unit with complaints of recurrent episodes of hemiplegia in the left side of the body with deviation of angle of the mouth. On arrival, the child had three episodes of hemiplegia over a period of 1 hour. There was no history of fever, headache, epilepsy, infections, chronic disease, or similar episodes in the past. Family history was also negative for any similar complaints or illnesses. Developmentally, the child was normal. The child was the first child of young non-consanguineous parents.

\section{On Examination}

The child was unstable, anxious, and afebrile, with normal hydration; all peripheral pulses were normally palpable. Blood pressure was 120/80 $\mathrm{mm} \mathrm{Hg}$, pulse rate 90/min, and RR 22/min. Examination of CNS showed all cranial nerves were intact. There was grade 0 power in left upper limb (UL) and lower limb (LL); power in right UL and LL was normal. In between the episodes, there was improvement in power in both left UL and LL. Reflexes in the left side of the body were absent and on the right side they were normal. There was no sensory deficit. Gait could not be elicited. There were no signs of meningeal irritation. All other systemic examinations were within normal limits.

Child was absolutely normal in between attacks. The initial blood examination showed no particularities with healthy hemoglobin of $14.6 \mathrm{gm} \%$, TLC 7960/ $\mu \mathrm{L}$, and platelets 2.4 lacs $/ \mu \mathrm{L}$. Blood sugar and electrolytes were also in normal range. Toxicological screening was negative.

Lipid profile had the following results: S. cholesterol (total) $-135 \mathrm{mg} / \mathrm{dL}$, S. triglyceride $-130 \mathrm{mg} / \mathrm{dL}$, S. cholesterol (VLDL) $-26 \mathrm{mg} / \mathrm{dL}$, S. cholesterol (LDL) $-62 \mathrm{mg} / \mathrm{dL}$, and S. cholesterol (HDL) $-47 \mathrm{mg} / \mathrm{dL}$, which was grossly normal.

Lumbar puncture was done to rule out CNS infection. Findings were as follows: Cell cytology - no nucleated cells seen, sugar -53 , protein -28 , grams stain and AFB stain - no organism seen, and CSF culture - sterile.

Magnetic resonance image of the brain was done, which showed subacute infarct in the right lentiform 
nucleus in the right middle cerebral artery. Magnetic resonance image angiography brain was normal. To elucidate the origin of an ischemic stroke at a young age, further examination was done for coagulation profile and immune markers with increased cardiovascular risk. Protein $\mathrm{C}-67 \mathrm{IU} / \mathrm{dL}$, protein $\mathrm{S}-72 \mathrm{U} / \mathrm{dL}$, lupus anticoagulant-absent, antinuclear antibodies - negative, DSDNA - negative, and anti-phospholipid IgG antibodies $-1.5 \mathrm{U} / \mathrm{mL}$. Basal homocysteine level was increased - 18.63 $\mu \mathrm{mol} / \mathrm{L}$ (ref.: 4.44-13.56).

A treatment with citicoline, folic acid, aspirin, and vitamin B12 was started. Gradually, episodes of hemiplegia subsided and the child was normal in a month.

Homocysteine level was repeated after 5 months, which was $-6.06 \mu \mathrm{mol} / \mathrm{L}$, in the normal range. Child didn't have any repeat episode of hemiplegia and was advised close follow-up in the future.

\section{DISCUSSION}

Homocysteine is a sulfurous amino acid that is formed as an intermediary product during the conversion of the essential amino acid methionine to cysteine. Normal homocysteine levels vary between 5 and $15 \mu \mathrm{mol} / \mathrm{L}$. Hyperhomocysteinemia is classified into three classes depending on the plasma levels: 16 to $30 \mu \mathrm{mol} / \mathrm{L}, 31$ to $100 \mu \mathrm{mol} / \mathrm{L}$, and >100 $\mathrm{mol} / \mathrm{L}$, which corresponds respectively to a light, mild, and serious form of hyperhomocysteinemia. ${ }^{3}$ There are various causes that can lead to hyperhomocysteinemia: Hereditary abnormalities that lead to disturbances of enzymes related to the homocysteine metabolism, vitamin deficiencies, and different other factors, such as, lifestyle factors, chronic renal insufficiency, hypothyroidism, pernicious anemia, systemic lupus erythematosus (SLE), end stage diabetes, cancers, and medication. ${ }^{3,4}$ In 1969, it was suggested for the first time that there was a connection between increased homocysteine levels and atherosclerotic diseases. This hypothesis was backed by different successive observational studies. ${ }^{3,5}$ Hyperhomocysteinemia is an independent risk factor for atherosclerosis of the coronary, cerebral, and peripheral blood vessels. ${ }^{3,6}$ The precise pathophysiological mechanism through which hyperhomocysteinemia enhances atherosclerosis and thrombosis is not yet fully known. It is known however that homocysteine causes endothelial cell injury and thereby initiates the process of premature atherosclerosis. Hyperhomocysteinemia is generally acknowledged as a risk factor for atherothrombosis diseases, but a causal relation between both has not yet been conclusively established. ${ }^{3,5,7}$ Because a causal relation between hyperhomocysteinemia and stroke is unclear, the question remains what's the place of diagnostics within the clinical practice. Moreover, there is insufficient evidence that reducing hyperhomocysteinemia also contributes to a lowering of the risk of stroke. ${ }^{8}$ Despite these findings, it is still advised to determine homocysteine levels for patients with an ischemic stroke because the therapy is safe and cheap. ${ }^{9}$ Furthermore, it is useful to determine homocysteine levels for patients with an ischemic stroke with no clue of vascular disease and thrombosis, an ischemic stroke at a young age, and a family history of premature atherosclerosis. ${ }^{3}$ At this moment, the American Heart and Stroke Association advises to treat patients with a stroke and hyperhomocysteinemia (>10 $\mu \mathrm{mol} / \mathrm{L}$ ) daily with $0.4 \mathrm{mg}$ folic acid, $2.4 \mu \mathrm{g}$ vitamin B12, and $1.7 \mathrm{mg}$ vitamin B6 because of the low cost and safety of the therapy. ${ }^{9}$ The normalization of the plasma homocysteine concentrations happens within 2 to 6 weeks after the start of the therapy. ${ }^{10}$

\section{REFERENCES}

1. Broderick J, Talbot GT, Prenger E, Leach A, Brott T. Stroke in children within a major metropolitan area: the surprising importance of intracerebral hemorrhage. J Child Neurol 1993 Jul;8(3):250-255.

2. Whisnat JP. Modeling of risk factors for ischemic stroke: the Willis lecture. Stroke 1997 Sep;28(9):1839-1843.

3. Kaul S, Zadeh AA, Shah PK. Homocysteine hypothesis for atherothrombotic cardiovascular disease. J Am Coll Cardiol 2006 Sep 5;48(5):915-923.

4. Vanbrabant P, Van Den Bosch G, Gheuens E, Baeck E, Nutten D, Neels H, Verbraeken H. Cerebrovasculair accident en hyperhomocysteïnemie. Tijdschr voor Geneeskunde 2001;57(6):463-468.

5. Wald DS, Law M, Morris JK. Homocysteine and cardiovascular disease: evidence on causality from a meta-analysis. BMJ 2002 Nov;325(7374):1302-1306.

6. Spence JD, Bang H, Chambless LE, Stampfer MJ. Vitamin Intervention for stroke prevention trial. An efficacy analysis. Stroke 2005 Nov;36(11):2404-2409.

7. Wald DS, Wald NJ, Morris JK, Law M. Folic acid, homocysteine, and cardiovascular disease: Judging causality in the face of inconclusive trial evidence. BMJ 2006 Nov;333(7578):1215-1217.

8. Boers GH, Smals AG, Trijbels FJ, Fowler B, Bakkeren JA, et al. Heterozygosity for homocystinuria in premature peripheral and cerebral occlusive arterial disease. N Engl J Med 1985 Sep;313(12):709-715.

9. Sacco R, Adams R, Albers G, Alberts M, Benavente O, Furie K, Goldstein LB, Gorelick P, Halperin J, Harbaugh R, et al. Guidelines for prevention of stroke in patients with ischemic stroke or transient ischemic attack: a statement for health care professionals from the American Heart Association/American Stroke Association Council on stroke: Co-sponsored by the Council on Cardiovascular Radiology and Intervention: the American Academy of Neurology affirms the value of this guideline. Stroke 2006 Feb;37(2):577-617.

10. Toole JF, Malinow MR, Chambless LE, Spence JD, Pettigrew LC, Howard VJ, Sides EG, Wang CH, Stampfer M. Lowering homocysteine in patients with ischemic stroke to prevent recurrent stroke, myocardial infarction, and death: the vitamin intervention for stroke prevention (VISP) randomized controlled trial. JAMA 2004 Feb 4;291(5):565-575. 